\title{
Graphical Layout of the Musical Preferences Studies: An Overview on How the Studies on Musical Tastes Are Conducted
}

\author{
Seyed Farhad Tayyebi ${ }^{*}$, Yüksel Demir ${ }^{1}$, Mehmet Nemutlu², Can Karadoğan ${ }^{3}$ \\ ${ }^{1}$ Department of Architecture, Istanbul Technical University, Istanbul, Turkey \\ ${ }^{2}$ Istanbul State Conservatory, Mimar Sinan Fine Arts University, Istanbul, Turkey \\ ${ }^{3}$ Music Technology Department, Turkish Music State Conservatory, Istanbul Technical University, Istanbul, Turkey \\ Email: ^tayyebi.sf@gmail.com, demiry@itu.edu.tr, mehmetnemutlu@gmail.com,karadoganc@itu.edu.tr
}

How to cite this paper: Tayyebi, S. F. Demir, Y., Nemutlu, M., \& Karadoğan, C. (2020). Graphical Layout of the Musical Preferences Studies: An Overview on How the Studies on Musical Tastes Are Conducted. Art and Design Review, 8, 6-30. https://doi.org/10.4236/adr.2020.81002

Received: December 16, 2019

Accepted: January 13, 2020

Published: January 16, 2020

Copyright $\odot 2020$ by author(s) and Scientific Research Publishing Inc. This work is licensed under the Creative Commons Attribution International License (CC BY 4.0).

http://creativecommons.org/licenses/by/4.0/

\begin{abstract}
Various studies have been exploring the numerous determinants form our musical tastes and some review papers classify them in a discursive manner to provide a more holistic understanding of the determinants. This study, as a similar endeavor, depicts the mains determinants of our musical preferences categorized with regards to our musical perception process via a graphical model. After dividing the internal and external factors, the model provides a layer-based structure illustrating both musical taste determinants and modes of investigation. This paper provides three layers of determinants. The basic layer reflects the trace of more fundamental aspects of music on our musical tastes, like tempo as well as aggressive or happy as perceived attributes. The classification layer discusses on the trace of some classes in musical appreciations, like genre and Big Five Model. As lastly, the skimmed layer, as the midst layer, illustrates the newly-developed factors summing up the determinants of our musical taste. The introduced three layers also classify the external determinants of our musical taste. Consequently, this study not only provides a more holistic understanding of the determinants but also reflects the gap among the conducted studies to provide a platform for further investigations.
\end{abstract}

\section{Keywords}

Musical Preferences, Musical Taste Determinants, Musical Taste Model, Musical Appreciations

\section{Introduction}

Music is interwoven with our lives and implanted in our cultural and social en- 
vironments over the ages. Nowadays, music is a ubiquitous form of art, coherently connected to people's everyday lives. Being among the most popular leisure activity, so much time and money, as well as energy, is being spent on it (Schäfer, Sedlmeier, Städtler, \& Huron, 2013). Many people pursue activities related to music and strive to present more satisfactory products. Thus, musical appreciation is a crucial issue for various aspects and very diverse people from music teachers to composers, performers, and producers. It can change the musical education activities, impact on performances, influence on production, and penetrate to marketing activities. It concerns the musical experience as a unique aspect of music.

Music preference is among the interests of many researchers in aesthetics, philosophy, psychology, musicology, and neuroscience. However, music taste studies experienced some fluctuations over history. Hevner's work in 1936 is among the earliest experimental research on musical preferences (Hevner, 1936). Although in 1950 Farnsworth discussed much on musical preference, from the 1930s to 1970s was the period of stagnation in the music appreciation explorations, which is followed by a revival period after 1970s (Leblanc, 1982). "The question of why different people like different music ... has received much attention from researchers especially in the last two decades" (Schäfer \& Sedlmeier, 2010). Although it just takes a few seconds to decide whether to ignore unpleasant music piece or to buy the album by pleased listeners (Greenberg, Baron-Cohen, Stillwell, Kosinski, \& Rentfrow, 2015), various specialists have revealed many variables influencing on music preferences including musical attributes, the listener's characteristics, performance issues, and environmental conditions; they constructed models and developed theories to give insight and to facilitate the understanding of musical tastes, though it is still an elusive not-solved issue.

Researchers have discovered a vast number of influential parameters on musical appreciation. The parameters, called as determinants of our musical taste, are categorized differently by various reviewers, with the hope of attaining a holistic insight on the determinant's roots. Wapnick published a comprehensive review and summarized the parameters via three categories: musical characteristics pertaining to musical stimuli, situational variables relating to community and social issues, and subjective variables including listener's character and personality (Wapnick, 1976). Finnäs via his extensive study reviews the determinants in four groups: specific characteristics of music, familiarity with music, "intramusically" and "intrapersonally" oriented factors, and social effects (Finnäs, 1989). Similarly, music preference determinants are also reviewed by focusing on music instruction and musical characteristics by Sink and Teo respectively (Sink, 1992; Teo, 2003). More recently, Schäfer \& Sedlmeier make another review on studies by concentrating on cognitive functions, emotional functions, physiological arousal, cultural and social functions, repetition and familiarity, and characteristics of music and listener; they found them all influen- 
tial on musical appreciation, though in varying levels of importance (Schäfer \& Sedlmeier, 2010).

Despite various attempts, the review papers do not propose a robust model to provide a more holistic insight on our music tastes determinants. The review papers are not univocal; despite some similarity, they categorized the influential factors differently, convoluting the roots of the determinants. In addition, in contrast to the discursive manner of the most review papers, a very few number of studies propose graphical layout. Every single discursive or graphical review papers have its unique perspective, to sum up the determinants. Despite the existence of numerous studies, there is still no conclusive theory of music preference; "we are still far from having full insight into mechanism that make us like it" (Schäfer \& Sedlmeier, 2010). Little is known about the roots and determinants of our musical tastes, and how it is investigated entirely.

This study, by scrutinizing several studies, aims to propose a graphical model for the music taste determinants and reflects how they are investigated in general. Started by extensive literature explorations and arranging a large number of studies, this study by introducing an initiative graphical layout strives to make a robust platform to give a better insight on the determinants, to reflect the gap and flaws among the conducted studies, to provide an assistive tool to design future studies in a more conscious manner, and finally to be a trigger to overcome the elusive subject of musical appreciation.

Worth mentioning, in contrast to the conventional papers proposing gist of the paper and supporting through the study, this paper proposes a basic raw model to make an overall perception and then completes it over the paper to facilitate data digestions. Accordingly, at first, a raw graphical layout is proposed in a way to reflect both the origin of the determinants and the way researchers conducted their studies in general. The graph illustrates the determinants via two main groups: Internal factors and External factors. In addition, among each group, the determinants are divided into two layers: Basic Layer and Classification Layer. Thus, after providing a matrix-like graph to gain a general understanding of the layout in the next part, the third and forth parts respectively focus on the Internal and External factor more in-depth. The determinant attributes within each category are then discussed with regards to the layer-based structure of the graph. Accordingly, during the paper progress, much more details are being integrated to the graph. Finally, arising from a very recent fruitful research, a new layer of determinants is then placed within the graph, discussed in the fifth part of the paper. The introduced layer of studies not only covers the most recent investigations but also reflects the substantial potential that exists in this layer, which still needs further explorations. Consequently, the graph which is completed during the paper progress provides a more in-depth understanding on the determinants of our musical taste and provides a platform for further investigation design. Please consider, through the paper, the outcomes of the conducted studies are presented in an accurately classified manner to support the graph integration, 
though discussed briefly to keep the review paper concise.

\section{Graphical Layout of Previous Studies}

There are two graphical models among the proceedings on musical tastes; each model has a particular perspective in providing the models. LeBlanc in his fruitful attempts collected a great variety of influential variables on musical preferences and finally provided a model to reflect the parameters in a hierarchical system. Proposed in 1980 and edited in 1981, the model illustrated the responding mode to musical stimuli in a glance via eight hierarchical variant roots; "flow of information" is the root of this graph (Droe, 2006). In 1986 the model integrated with the sources of the variables: 1) physical characteristics of the music itself, 2) cultural environment in which the listener lives and 3) personal characteristics of the listeners (LeBlanc \& Sherrill, 1986). A more recent graphical model, called as "Reciprocal feedback model of musical response", reflects the process of like/dislike reaction to music (Hargreaves, MacDonald, \& Miell, 2005). This graphical model mentions the root of the musical tastes via music related issues (genre, familiarity, complexity, live, recorded), situations and contexts (social and cultural contexts, presence/absence of others), and listener (gender, age, personality, musical knowledge), which all gathered in an instant decision making procedure. In both graphical models and other discursive studies, musical attributes, personal issues, and environmental conditions are the most discussed roots of musical preferences.

Our model is initiated on a simplified decision-making process, starting from listening to music to the immediate like-dislike reaction, regardless of the long-lasting effects of music and its trace on musical preferences. Generally speaking, music starts its journey as an audible stimulus; an individual by his unique personal attributes receives them under an environmental condition, and perceives some attributes of the music; then the first preference decision can be made. This general process reflects four primary roots: The basic musical attributes, our personal issues, environmental conditions, and the perceived attributes. Regarding the conducted investigations, these four issues are divided into two parts: Intra-music factors including the basic music attributes and so-called perceived psychological attributes, and Extra-music factors including personal attributes and environmental conditions (Figure 1, top part). As the model shows, the basic music attributes stimulate some musical qualities as the perceived attributes; a single-sided arrow reflects this one-sided relation. Moreover, the reciprocal interrelations between the personal issues and environmental conditions are illustrated by the double-sided arrow between the factors in the model. Worth noting, the order of the influential factors on the decision-making process of the listener are just arranged in a way to facilitate the perception of the model, though, in reality, all these four categorical attributes interrelate concurrently, as the music plays in time.

There are a large number of attributes, known as determinants or variables, in 
Intra-Music Factors

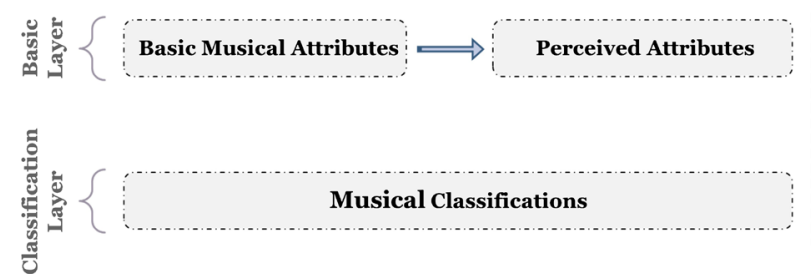

Extra-Music Factors

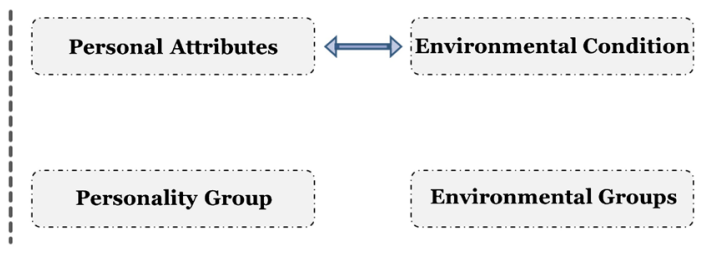

Figure 1. Main source of music attributes.

each of these four illustrated categories. Many researchers design their research by focusing on a few attributes within each group. On the other hand, instead of concentrating on some specific attributes, other researchers focus on musical classifications as a collection of various attributes. For example, instead of concerning tempo and mode as primary musical attributes, the genre as a representative of some characteristics is being investigated. Similarly, some studies focus on personality types in music taste studies instead of concerning some vivid personal attributes. The model illustrates this set of studies concerning the sum of different characteristics in Classification Layer, while the attribute-based modes of studies are presented in Basic Layer (Figure 1). Although the model integrates over the paper, there are rare studies outside of these layers.

Rooted either in basic or classification layers, some studies aim to find a direct relationship between the variables and musical preferences; while other studies find a relationship between the attributes either within one classification or between the categories. For instance, some studies directly explore the effect of tempo as a basic music attribute or genre as a musical classification on music appreciations; while other studies investigate the relationship between the listener's gender and the preferred tempo. In contrast to the first set of studies that directly concern musical satisfaction, the later studies indirectly cooperate in music preferences. Worth mentioning, the direct relationship between the variables and musical preferences is mostly investigated among intra-music factors and the basic layers of study involving musical qualities. Regarding the viability of the studies, expectedly, the extra-music factors are mostly investigated in relation to the intra-music factors, either with or without concerning musical preferences. Over the paper, the studies are discussed by concerning their direct and indirect influences on musical preferences.

\section{Intra-Music Factors}

The intra-music factors concern the determinants of musical appreciations within the realm of music. The intra-music oriented investigations, as Figure 2 shows, have three main categories: 1) Basic Musical Attributes covers the fundamental notions in the musical realm, like tempo, rhythm, harmony and so on. 2) Perceived Attributes, also called as psychological attributes, concerns the main characteristics of music, like descriptive words ascribed to a music, such as happy, sad, sorrowful, fearful, and aggressive, and etc. 3) Musical Classifications 


\section{Intra-Music Factors}

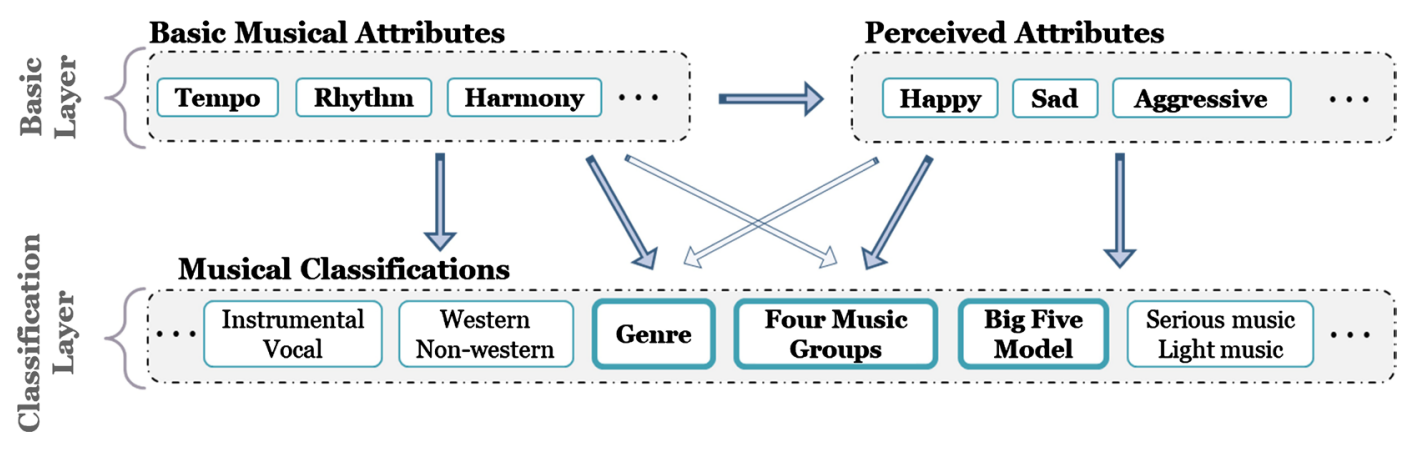

Figure 2. Intra-music factors.

considers the integral categorization of music pieces, either via its basic musical attributes or perceived attributes or a combination of both (Figure 2). The subsequent sections discuss each category separately.

\subsection{Basic Musical Attributes-Basic Layer}

The first set of studies explores the direct relationship between the basic musical parameters and musical appreciation. These investigations consider the most rudimentary musical terms, including tempo, rhythm, pitch, harmony, loudness, complexity, melody, dissonances, and even the language of the lyrics, which all covers in the Basic Layer of determinants. Investigating the general relationship between basic musical attributes and musical appreciation forms the first mode of investigation in this category. For example, there is a consistent finding on musical harmony that the octave, perfect fifth, and perfect fourth are respectively the most preferred consonant intervals, in contrast to diminished second having the most repulsive dissonant intervals (Davies \& Barclay, 1977). In a similar vein, V-I is the most preferred cadence, which never substitutes for any other progression as well as the inversions (Rosner \& Narmour, 1992). Another study shows the enjoyment follows an inverted U-shape in complexity level of non-vocal music pieces; a moderate complexity level is the most preferred range from simplicity to hardly complex musical compositions (Gordon \& Gridley, 2013). Teo, similar to Wapnick (Wapnick, 1980), shows that pitch does not significantly influence musical preferences, and both high and low pitch had played a part in musical satisfactions (Teo, 2003). Lastly, another study shows that language has a direct influence on musical preferences; comparing English and German, listeners prefer the familiar over the unfamiliar language of lyric (Gosselin, 2017).

As the second mode of investigation, some scholars apply limitations to either make their study doable or compare the results between the limited categories. For example, in a study limited to children, higher preference rate is observed in higher tempo; it shows, a "strong positive correlation between increases of tempo and higher preference ratings" for children (LeBlanc \& McCrary, 1983). Another study limited to musicians shows that listeners generally preferred the 
increased levels of tempo for slow excerpts and the decreased tempo for original music pieces (Geringer, 2010; Yarbrough, 1987). Furthermore, many studies compare the trace of basic musical attributes on musical appreciation among different categories, like comparing graduate and undergraduate students (Geringer, 1976) as well as males and females; for instance, LeBlanc and Sherrill explore the effect of genders on preferred singer's gender (LeBlanc \& Sherrill, 1986).

In contrast, other studies apply some limitations to mainly discover the preference roots, though they also illustrate the relationship between basic musical attributes and musical preferences. These studies, gradually increasing among the neuroscientists, apply demographical limitations to the audiences. For instance, a study limited to 4-month old infants shows that "infants are biologically prepared to treat consonance as perceptually more pleasing than dissonance." (Zentner \& Kagan, 1998). Although the investigation shows more satisfaction is achievable by a consonant, the study mainly reflects the biological root of the consonant preference. The idea is followed by other researchers and resulted in discovering the relationship between the pitch notes and the physiological neurons sensing the frequency (Tramo, Cariani, Delgutte, \& Braida, 2001). Please consider, this type of study should not be mixed with another set of studies exploring the relationship between musical attribute preferences and biological attributes like brain empathy level, brain type, and so on; these studies concern more with the extra-music factors, rather than intra-music attributes, to find its direct impact on musical preference among the limited number of listeners.

The last mode of studies considers more than one parameter simultaneously, to find their correlations and their importance hierarchy on musical appreciations. For example, considering both scale and tempo, a study shows that the order of enjoyment range is fast major, slow minor, fast minor, slow major (Husain, Thompson, \& Schellenberg, 2002). Another study, comparing intensity and consonance shows that intensity was the more significant determinant of preference; the effect of dissonance on preference was negligible (Martindale \& Moore, 1990). About the importance of pitch, tempo, and timber in a melody, a study shows the timber of melody is more kept in our memory than pitch and tempo, though melody identification is independent of the mentioned surface features (Schellenberg \& Habashi, 2015). Although many paper reviews summarize the influential factors on music preferences like tempo, rhythm, pitch, harmony, and loudness (LeBlanc, 1981; North \& Hargreaves, 2008), some paper reviews make their endeavors to provide an order for the influential factors on musical preferences. For example, Finnäs conclude that higher preference tends to be aroused orderly by fast tempos and distinct rhythm, coherent melodies, absence of pronounced dissonances, and a moderate degree of complexity (Finnäs, 1989).

Consequently, three investigation modes exist in exploring the direct relationship between basic musical attributes and musical appreciation, including 
exploring the trace of limited number of attributes on musical appreciation in general, investigations within limited participants to compare the outcome among the categories or reflect the root of the musical preferences, and lastly considering various attributes to reflect the importance hierarchy. Since these attributes are the rudimentary attributes of music, there is just direct investigation of their trace on musical appreciation.

\subsection{Perceived Attributes-Basic Layer}

Another set of studies concerns the interrelation between perceived psychological attributes and musical taste. As Frijda made an extensive discussion (Frijda, 2008), emotion in music is an extensively discussed issues in musicology. Some scholars believe that "music does not, of course, literally contain or express emotion." (Evans \& Schubert, 2008); while as psychologists also confirm (Juslin \& Sloboda, 2001), many musicians believe that music can express, induce, change, strengthen, and mitigate emotion (Schäfer \& Sedlmeier, 2010). Even some scholars discuss the relationship between expressed and perceived emotion (Gabrielsson, 2002; Evans \& Schubert, 2008). Despite the existence of different points of view, according to Davies, "we ascribe an emotion to a music since there are similarities between expressing a particular emotion and as a music sounds to us!" (Davies, 2003). Regarding the fact that music is one of the most efficient means for triggering moods, at least, we can feel an emotion in response to music.

Many scholars reflect the trace of perceived attributes or emotion on musical satisfaction. Not only they investigate on what emotions can a music express, but also they explore on its direct effect on musical appreciations. As Finnäs in his fruitful review paper discussed the precedent studies (Finnäs, 1989), the trace of 38 emotions and attributes are listed and investigated in more recent studies (Juslin \& Laukka, 2004; Lindström, Juslin, Bresin, \& Williamon, 2003; Rentfrow et al., 2012). According to the papers, the perceived attributes do not possess the same significance value while concerning musical appreciation; happiness, sadness, fear, anger, and tenderness, and love are the most robust reflector of musical tastes. Accordingly, some studies limit their scope with the fewer number of emotions (Eerola \& Vuoskoski, 2013). Although this type of studies criticized by not having a clear definition for the attributes (Cespedes-Guevara \& Eerola, 2018), and neglecting social context (Juslin \& Laukka, 2004), many studies investigate the direct relationship between the perceived attribute and musical satisfaction.

Another set of studies by exploring the relationship between the perceived attributes and other factors like basic music attributes indirectly concern the trace of emotion in musical appreciations. As Rigg suggested the influential effect of tempo on emotional suggestiveness (Rigg, 1940), fast tempo indicates happiness and restlessness, slow tempo express dignity, calmness, and sadness (Hevner, 1937). Another more recent study confirms that fast tempos associate with other terms such as happy, fear, and anger (Gabrielsson \& Lindström, 
2001). Apart from the trace of musical tempo on arousal, there is a relationship between the musical mode (major/minor) on musical mood (happy/sad) (Husain et al., 2002); even musical structure influence on the perceived emotional expression (Gabrielsson \& Lindström, 2001). Lastly, Guevara and Eerola in 2018 made a review on various studies, and tabulated a list of relationships between the basic musical parameters and musical psychological attributes (Cespedes-Guevara \& Eerola, 2018). Consequently, this set of studies by exploring the relationship between the basic musical attributes and the perceived attributes indirectly reflect musical appreciations, though not concerning musical taste.

\subsection{Musical Classifications-Classification Layer}

This set of studies concern musical classifications and their trace on musical satisfaction. Every single music attribute can be a root for classifications, like tempo (fast/slow), timber (vocal/instrumental), instrumental texture (monophony/polyphony), and even perceived attributes (sad, happy, scary, and tender) (Vuoskoski, Thompson, McIlwain, \& Eerola, 2012). Although these studies have a trace of classification, they are located in the basic layer of studies instead of classification layer (Figure 2). This group of studies involves the categorization based on different factors, for example, categorizing music into serious and light, or dividing them into folk, art, and popular music which "each of these three is distinguishable from the others according to certain criteria" (Tagg, 1982). As another method of classification, we may find one parameter as a primary factor accompanied by some secondary issues; for example categorizing music based on context as liturgical/secular, location as western/non-western (Teo, 2003), era or historical features as tonal/atonal or tonal/post-tonal (Tymoczko, 2010). In this case classifications is not merely basin on one attribute, accordingly can be regarded in the musical classification studies. Among the variety of classification in musical studies concern musical appreciation, finally, 3 groups are discussed briefly as evidence of this mode of investigation on musical taste: Genre, Four music groups, and Big Five Model.

Genre as a musical categorization is probably the most popular music descriptor and organizer of large digital music databases. There is a bunch of data in our digital-oriented world that shows a direct relationship between the music preference and genre, as it is reported country and rock are the most favorite music genres in America (Backus, 2018). YouTube, Pandora, Spotify, Amazon Prime Music, and other worldwide music sources by having access to the digital data provide periodic reports on each music genre preferences in various geographical or listener's ages (Swanson, 2015; Delmonte, 2017; Lopes, 2018). Furthermore, genre has penetrated into studies on musicology; regardless of being the main aim or not, they reflect the direct influence of genre and musical satisfaction. For example, Schäfer \& Sedlmeier report that rock, pop, and classical music were liked most in their study (Schäfer \& Sedlmeier, 2009). Genre as a musical classifi- 
cation is directly considered in musical taste explorations.

Some other studies by finding the relationship between genre and musical attribute indirectly cooperate on musical preferences. If genre is an intrinsic attribute or extrinsic description of music (Aucouturier \& Pachet, 2003), the relationship between the musical attributes and musical genre is an ongoing platform for studies. For example, some scholars reflect the relationships between genre and repeating patterns in rhythmic or melodic sequence (Lin, Liu, Wu, \& Chen, 2004), music lyrics (Neuman, Perlovsky, Cohen, \& Livshits, 2016) timbre, rhythm and pitch (Brecheisen, Kriegel, Kunath, \& Pryakhin, 2006). Furthermore, by applying and discovering the relationship between the genre and musical features, many studies compete on automatic genre classifications (Rosner et al., 2014; Vatolkin, Rötter, \& Weihs, 2014; Cheng, Yang, Lin, Liao, \& Chen, 2008). Although genre categorization has traditionally been performed manually and "human beings were not able to classify correctly more than $76 \%$ of the music pieces" (Lippens, Martens, \& De Mulder, 2004), nowadays by considering multiple features of music, automatic genre classification increases the accuracy of classification to $80 \%$ (Costa, Oliveira, Koerich, Gouyon, \& Martins, 2012; Lo \& Lin, 2010; Costa, Oliveira, Koerich, \& Gouyon, 2012). Consequently, genre as the most well-acknowledged music classification cooperates in music preference studies in both direct and indirect manner.

In contrast to genre mostly involve basic musical attributes, the main four groups of music and the big five model concern more about the perceived attributes and emotions in music pieces (Figure 2). Thus, each category in both groups named in a way reflects the perceived attribute it may raise. Rentfrow \& Gosling introduce the main four music groups as Reflective \& Complex, Intense \& Rebellious, Upbeat \& Conventional, and Energetic \& Rhythmic (Rentfrow \& Gosling, 2003). In big five model, known as MUSIC called after their acronyms, consists of Mellow (smooth and relaxing, romantic), Unpretentious or Urban (uncomplicated, relaxing, unaggressive, rhythmic and percussive music), Sophisticated (complex, dynamic, and inspiring attributes), Intense (loud, aggressive, forceful, and energetic, not relaxing), and Contemporary or campestral (percussive, electric, and not sad) (Rentfrow, Goldberg, \& Levitin, 2011).

In contrast to the long background of genre, these recently-developed modes of classifications have been employed in various studies on musical preferences. These classifications mostly exist in studies that indirectly cooperate with musical preferences; many studies explore the relationship between genre and the classes. For example, R \& C mostly relates to blues, jazz, classical, and folk music, I \& R relates to rock, alternative, and heavy metal music, U \& $\mathrm{C}$ relates to country, soundtracks, religious, and pop music, and $\mathrm{E} \& \mathrm{R}$ relates to rap/hip-hop, soul/funk, and electronic/dance music (Rentfrow \& Gosling, 2003). Similarly, among the big five model, each group correlated with some genres: $M$ (soft rock, R\&B, and adult contemporary), $\mathrm{U}$ (country and folk), S (classical, operatic, avant-garde, world beat, and traditional jazz), I (classic rock, punk, 
heavy metal, and power pop), and C (rap, electronica, latin, acid jazz, and euro-pop) (Rentfrow et al., 2011). Arising from these relationships, Short Test Of Music Preferences (STOMP) and its revised version (STOMP-R) are also introduced to extract musical taste based on genre satisfactions. These categorizations need further investigations on directly-concerned musical tastes. Regarding the aim of the study, having few but the most robust examples suffices to confirm the existence of musical classifications in musical preference studies, either in a direct or an indirect manner.

\section{Extra-Music Factors}

Apart from the factors within the realm of music, there are some external factors that affect our musical preference. They are like secondary issues interrelating our musical taste. Although some studies directly concern the relationship between external factors and musical tastes, most of the studies explore the relationship between extra-music factors and intra-music factors which indirectly cooperate with our musical preferences. As Figure 3 shows, the extra-music factors consist of two main categories that interact with each other: the listener's attributes shared for various music pieces, and environmental condition shared among various listener of a performance. The personal and environmental issues are the roots of these variables, which are discussed separately in both basic and classification layers.

\subsection{Personal Attributes-Basic Layer}

Researchers always consider personal issues as one of the primary roots of our musical tastes; even many researchers explore the impact of various personal attributes, either permanent or temporal, on musical preferences. Starting from the most stable long-lasting features and characteristics of listeners, many studies discuss the interrelation between musical appreciation and age, ethnicity, gender (LeBlanc, Jin, Stamou, \& McCrary, 1999), social class, family background (Finnäs, 1989), and education (LeBlanc, Sims, Siivola, \& Obert, 1996). For instance, Finnäs in his review paper echoes that music is more important for younger; comparing older adults, they are more open to diverse music and have

\section{Extra-Music Factors}

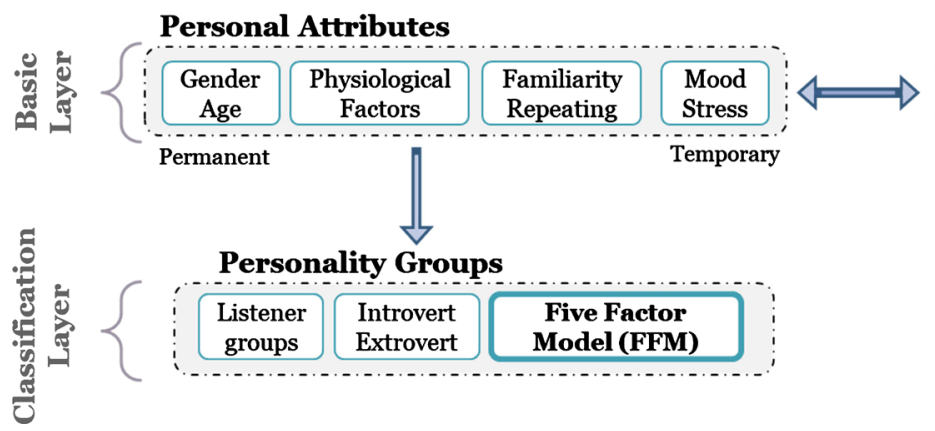

Environmental Conditions

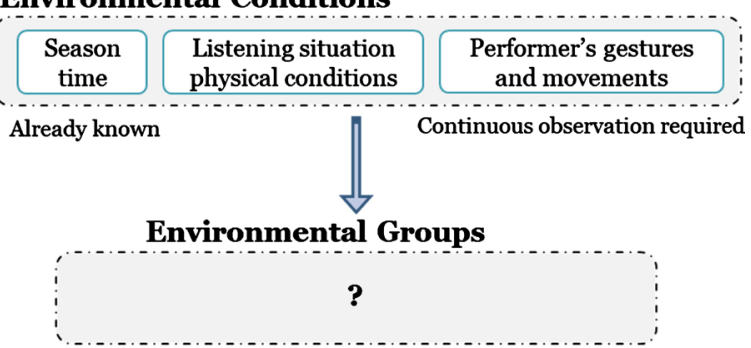

Figure 3. Extra music factors. 
a fewer prejudiced attitude toward certain kinds of music (Finnäs, 1989). On the other hand, several studies investigate the relationship between personal attributes and preferred attributes of music, indirectly cooperate on our musical taste. For example, as the listeners' sex influences on their vocal vibrato preferences (LeBlanc \& Sherrill, 1986), females like popular music styles more than males (Rawlings \& Ciancarelli, 1997); adversely, males prefer louder and enhanced bass and sad music more than females (Chamorro-Premuzic, Fagan, \& Furnham, 2010; McCown, Keiser, Mulhearn, \& Williamson, 1997). Even the listener's occupation has an influence on tempo preferences (Foley, 1940). The trace of race exists in musical preferences; listeners with strong racial associations prefer to listen to music that communicates about their racial identities (Marshall \& Naumann, 2018).

Among the more permanent attributes, the physiological factors influence on musical tastes. For example, the empathy levels of the brain positively correlated with preferences for mellow music including in $\mathrm{R} \& \mathrm{~B}$, soul, adult, contemporary, and soft rock genres, and negatively correlated with preferences for intense music exists in punk, heavy metal, and hard rock genres (Greenberg et al., 2015). As there is a relation between brain type and satisfactory instrumental acoustic features (Greenberg et al., 2015), the preferred tempo range relates to the frequency of the motor cortex of the listener's brains. Although "every individual has a preferred musical tempo, which peaks slightly above 120 beats per minute", the preferred tempo relates to neural activity explaining individual variations (Bauer, Kreutz, \& Herrmann, 2015). Regardless of the more in-depth physiological trace, these brief examples suffice to reflect the effects of physiological impacts on our music tastes.

Familiarity with music, as an individual factor, influence on our musical preferences. In contrast to painting, no relation was found between music education and emotional responses to music (Miu, Pițur, \& Szentágotai-Tătar, 2016); otherwise, having academic musical education can significantly alter our musical tastes (Sink, 1992). Musicians recognize familiar musical phrases better than non-musicians, and they are better in musical perception as well (Besson \& Faïta, 1995). Research results also confirm musician listener enjoys more than non-musicians on modern jazz (Gordon \& Gridley, 2013). Even familiarity with music pieces can positively influence their preferences. For example, there is a positive relationship between the frequency of listening and liking (North \& Hargreaves, 1995), and preference of musical pieces may increase after repeated listening, especially music pieces with more complexity (Finnäs, 1989; Schäfer \& Sedlmeier, 2010). Finally, scholars' investigations confirm that familiarity with music realm influences on our musical preferences.

Another set of studies investigates the impact of temporal listeners' attributes on music preferences like prior mood, being under pressure, feeling tired, or having severe stress, and so on. As mood affects cognitive performance (Husain et al., 2002), temporary listener mood influences on the processing of emotions, 
causing trait- and mood-congruent biases (Vuoskoski \& Eerola, 2011); while individuals with sad prior mood were not reliably inclined to listen to sad music, but they all apparently found choosing happy songs inappropriate (Friedman, Gordis, \& Förster, 2012). Comparing to painting, prior mood was considered more important about emotional responses to music (Miu et al., 2016). Even temporal condition of a composer influence on his/her musical compositions; those who have physical and mental stress has more originality in their melodies (Simonton, 1980). Consequently, all of these personal attributes categorized from the most permanent to the most temporal attributes can influence on our musical taste and their direct and indirect traces are investigated by scholars.

\subsection{Environmental Conditions-Basic Layer}

Environmental conditions influence on our preferred music pieces and musical tastes in general. People may listen to different music pieces while sitting home lonely or standing in a dance club with their friends, expecting smooth-relaxing music and cheerful music to rock people respectively. Many environmental issues alter our musical preferences like performance atmosphere, performer's gesture, time and even season. They might have a latent essence and not acknowledged in many studies and accordingly criticized by some scholars. Sensory perception can distinguish intra-music attributes from environmental conditions. While we listen to a music in a live performance, the sound quality, probable variations of tempo, loudness, articulation, intonation, and deviations in note timing and other audible issues influencing on our musical experience (Gabrielsson, 2001) should be considered as intra-music factors; On the other hand, the performers' gender, ethnicity, posture, and performing movements which are mostly visually-perceivable attributes are among the environmental conditions. From the sensory-based point of view, the environmental attributes are classified from the most already-known invisible factors like season to the visible factors need continuous observation like performer movements.

The first set of studies concerns the most covert but already known environmental attributes unattached to sensual perceptions, like season, time of day, and even geographical situation. For instance, musical selection may reflect seasonal influences, though refused by Yu and Kang (Yu \& Kang, 2010); “To every song, there is a season ... reflexive and complex music when primed with fall/winter and energetic and rhythmic and upbeat and conventional music when primed with spring/summer" (Pettijohn, Williams, \& Carter, 2010). As having a war zone experience as an environmental condition may increase the length of the melodies (Cerulo, 1984), geographical regions and being near to centers of musical activity influence on originality of composer's work (Simonton, 1986). These brief samples reflect their trace on musical appreciations, though not thoroughly acknowledged and need further consideration.

The second set of variables needs a shade of sensual perception like the holistic understanding of the atmosphere, which is perceivable with a glance. Fol- 
lowing the critique on disregarding the context in experimental studies on musical preferences (Konecni, 1982), North and Hargreaves "predict that the characteristics of preferred music may also vary with the situation in which that music is experienced". In an extensive study on 17 verbally-described situations, they confirm that "musical preferences vary in a consensual manner over a range of listening situations" (North \& Hargreaves, 1996). Similarly, another study confirms the importance of physical context and the presence of other people on emotional responses to a piece of music (Miu et al., 2016). Although studies in this field are scarce, the medium which music is listened through, physical condition of the listening place like temperature and color, as well as, famousness of the performance room and performers, general attributes of the performers group size of an orchestration in live music may influence on our music satisfactory level, which all need further examinations.

In a similar vein, another set of studies reflect the environmental conditions that need a continuous observation, like performers' posture, movements, and facial gestures, as well as their ethnicity and skin color. As Morrison discussed the importance of observing the performer group (Morrison, 1998), McCrary explored the trace of race on musical appreciations, confirmed that both black and white listeners provided more positive responses to their racial group (McCrary, 1993); similarly, another study reflects that "white subjects preferred [the music performed] by white performers regardless of presentation condition" (Morrison, 1998). Even the body movement of the performer plays an essential role in the communication between the performer and audience, and accordingly the enjoyment rates (Broughton \& Stevens, 2009). Reflecting the importance of the performer existence, live music is more effective than recorded one on mood enhancement and relieving tension on patients (Bailey, 1983). Noteworthy, being related to our visual senses, the trace of these external issues on music preferences might be affected by simply closing our eyes over the music experience. Consequently, the general attributes of environmental conditions, from obvious already known features to the changeable attributes requiring continuous observation, can be among the environmental determinants which affect our musical appreciations. Since not being involved in the classification, they are all placed in basic layer of determinants (Figure 3).

\subsection{Personality Groups and Environmental Categories -Classification Layer}

Apart from the personal attributes in the basic layer, personal groups as an issue in the Classification Layer reflect another set of determinants of our musical taste. Each previously discussed attributes of the listener can be a classification criterion, from the most permanent factors like gender and ethnicity to more temporal listeners' conditions like mood and situational stress. Although each classification is applicable in studies, regarding the categorizations of our paper, the studies applying one-item classifications fit more in the basic layer of studies. 
Instead, the categorizations consider various attributes fit more in the classification layer of our paper (Figure 3). For example, the listeners based on the importance of music to them are divided into three groups: high-, medium-, and low-involved listener (Ter Bogt, Mulder, Raaijmakers, \& Nic Gabhainn, 2011). Thus, the importance of music to the listener, which can be rooted in various personal issues, can be classifier which fits more in the classification layer of determinants.

Music preference seems to be a psychology-oriented decision; not only personality traits can interrelate musical appreciations (Vuoskoski \& Eerola, 2011), but also musical preferences can be indicative of an individual's personality (Langmeyer, Guglhör-Rudan, \& Tarnai, 2012). Accordingly, the trace of psychological classifications exists in many studies on musical taste, like introvert and extrovert people. For instance, the investigation's results show that "extraverted subjects are inclined to enjoy popular music" (Rawlings \& Ciancarelli, 1997), and they prefer upbeat and conventional and energetic and rhythmic types of music like rap and hip-hop, despite some gender differences (Langmeyer et al., 2012). Even among the musicians, extraverts showed a preference for "emotional" music and introverts for music with formal structure (Payne, 1980). Introvert and Extrovert people can also be considered as an issue fits more on the classification layer of determinants.

A robust classification is the main five-factor model of personality, known as FFM. Following Norman's study (Norman, 1963), The model passed a long way to suggest that the taxonomy of personality can be described through five major traits: 1) Extraversion, E-type, involves an energetic approach to the social and material world and includes traits such as sociability, activity, and positive emotionality; 2) Agreeableness, A-type, involves a pro-social and communal orientation and includes traits such as altruism, tender-mindedness, trust, and modesty; 3) Conscientiousness, C-type, describes socially prescribed impulse control and goal-directed behavior; 4) Neuroticism, N-type, involves negative emotionality and feeling anxious, sad, and tense, it sometimes referred to through its opposite pole as emotional stability; 5) Openness to experience, O-type, describes the breadth, depth, and originality of the person's mental and experiential life (John \& Srivastava, 1999; McCrae, 2009). This model has applied in many studies in psychology as well as musicology, though SAPA project aims to improve this robust personality classification (Condon, 2018). FFM is accordingly visible among the determinants within the classifications layer.

Worth nothing, despite being introduced in recent decades, FFM applied in many studies on musical taste. As a result of being in the classification layer of extra-music factors (Figure 3), expectedly, most of the studies applying FFM focuses on the relationship between each category and preferred musical attributes; they indirectly reflect musical taste. For example, the E-type individuals like happy music, and O-type prefer listening to complex music (Chamorro-Premuzic et al., 2010); confirmed by Langmeyer and his colleagues, 
there are positive correlation between music preferences of O-type individuals and complex, intense, and rebellious music, and negative correlation for upbeat music (Langmeyer et al., 2012). Similarly, another study triangulating between FFM, musical preferences, and physiological attributes; it shows a positive correlation between being an O-type, liking for sad music, and empathy level of the brain (Vuoskoski et al., 2012). In addition, there are some other studies considering the relationship between the FFM classification and music genres; for instance, O-type participants prefer blues, jazz, classical, and folk genres (Greenberg et al., 2016; Langmeyer et al., 2012); E-type and A-type people prefer pop, soundtrack, religious, soul, funk, electronic (Greenberg et al., 2016).

In contrast to the personality group as a category on classification layer of determinant, the environmental issues have not experienced any classification in studies related to musical taste. Although some studies have applied some environmental limitation, the trace of environmental issues especially via some classification are not well discussed. Thus, as Figure 3 shows, there is a gap among the studies on musical taste focusing on environmental conditions especially in a more classified manner. Future study can develop some models and explore their trace on musical appreciation.

\section{Skimmed Factors as a New Layer}

Regarding the proposed model of investigations, most of the studies are located either in the basic or classification layers, concerning Internal or External factors. Each layer has some flaws and accordingly encountered some critiques. For example among the internal factors, a large number of studies in the basic layer reflect a very diverse and uncountable number of determinants for music preferences. This large number of variables in one hand reflects the complexity of music preferences, on the other hand, prevents having a general understanding of the most influential factors on music preferences. Although some researchers discussed 38 perceived attributes, it is criticized they do not reflect the actual musical attributes that people like (Greenberg et al., 2016). Studies on the classification layer also faced many critiques. Genre as the most significant one is criticized by many theoreticians and researchers for being ambiguous and subjective (Lippens et al., 2004; McKay \& Fujinaga, 2006); “Does 'rock' music refer to The Beatles, Bob Dylan, or Jimi Hendrix? Pop music refers to Michael Jackson or Justin Bieber?” (Greenberg et al., 2015). Genre cannot capture information about an individual's preferences accurately. Furthermore, "Genres have little to do with the actual characteristics of the music." (Greenberg et al., 2015). Consequently, genres are subjective annotations with illusive definitions and social connotations, without concerning the musical attributes, thus cannot be categorized reliably (Greasley \& Lamont, 2006).

The high number of variables in the basic layer and the problematic aspects of classifications result in introducing a new set of study on musical preferences. This set of study is introduced to, on the one hand, make the uncountable num- 
ber of variables more manageable, and on the other hand to limit the problems within the classification layer. It is more like a summary of the primary variables, which reflects the most significant ones. Accordingly, the newly developed studies can fit neither in the basic layer nor classification layer, rather in a new layer of study in-between. They concern a limited number of significant attributes rooted in musical essence, without applying any classifications; this layer called here as Skimmed Layer (Figure 4). Although some review studies echo a hierarchy for some of the influential factors, it seems they do not cover all the significant ones; the studies on the introduced layer summarize the influential attributes on our musical tastes. Consequently, the Skimmed Layer is integrated to our model to reflect the rare but profound studies on musical preferences, as well as to make a platform for further investigation.

Various attempts have made by many researchers to provide a viable list of influential attributes on our music preferences, like years of investigations by Greenberg and his colleagues (Greenberg et al., 2015, 2016). Finally, in a robust investigation with thousands of participants, they introduced three main factors deeply rooted in our musical taste: Arousal which reflects the energy level of the music, Valence that shows sad to happy emotions in the music, and Depth that concerns the sophistication and emotional depth in the music (Greenberg et al., 2016). Apart from the direct relationship between these three factors and musical preferences, the study reflects the correlation between them and five personality types, as well as 38 perceived attributes of music, indirectly cooperate in musical taste. For example, high arousal dimension positively correlates with intense, forceful, abrasive, and thrilling and negative loading of arousal correlates with gentle, calming, and mellow; "Highly on valence component were fun, happy, lively, enthusiastic and joyful and those that had high negative loadings were depressing and sad." And lastly, high depth reflects intelligent, sophisticated, inspiring, complex, and poetic music, and negative depth echoes the party music and danceable attributes (Greenberg et al., 2016). Finally, although this study explores the direct and indirect relationship between the three factors and musical preferences, this layer of studies needs further investigations especially among the extra-music attributes.

Intra-Music Factors

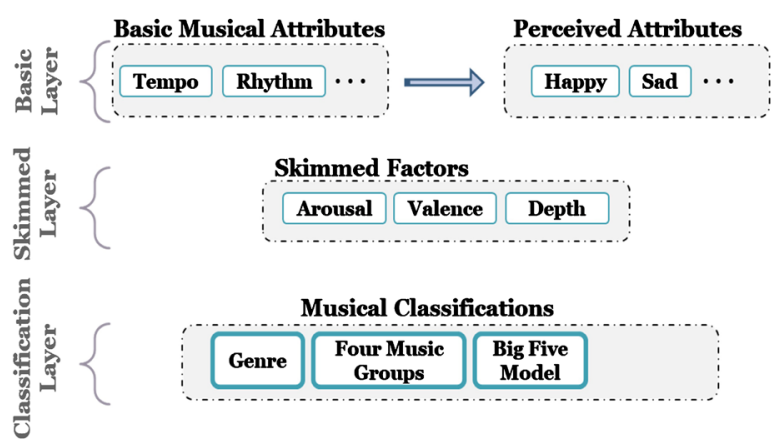

Extra-Music Factors

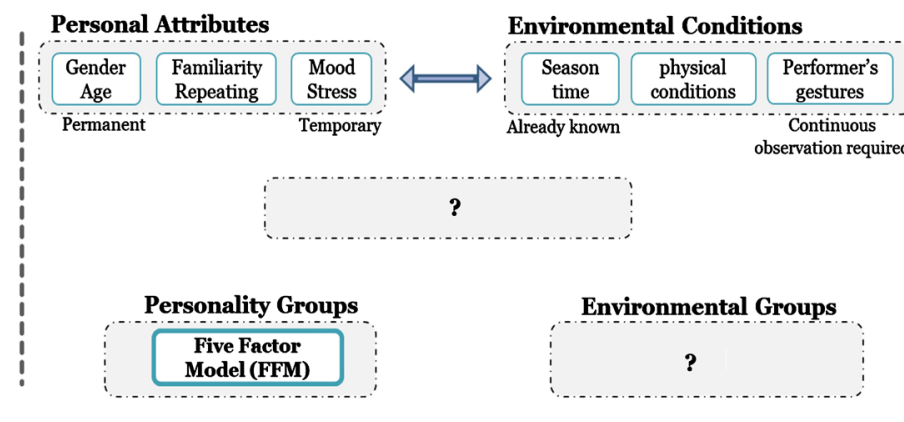

Figure 4. Skimmed layer and the final layout of music taste studies. 


\section{Conclusion}

The model is the primary outcome of this study. By focusing on temporal like/dislike reaction to music, at first, the study reflects the main four roots of our music preference determinants. As the model first presents, there are four roots for the musical appreciation. 1) The basic musical attributes indicate the trace of the fundamental elements of music on our musical appreciations, like tempo, mode, and harmony. 2) The perceived musical attributes concern the comprehensible qualities of the music and how a piece of music is felt; these attributes can be another set of determinants of our musical taste. 3) Personal attributes concern the listener criteria within a spectrum from the most permanent issues like gender and ethnicity to the very temporal factor, like having stress while listening to music. 4) The environmental conditions cover the environmental factors from the already known issues like season and time to the factors that require continuous observation, including performer gestures and movements. Having them together in a categorized manner can provide a better perception of the influential factors on our musical preferences.

The integrated model through the paper introduces three layers of determinants in the exploration of musical tastes. These layers, on the one hand, by giving an insight into the musical taste determinants make a better perception of the conducted studies, and on the other hand, illustrate the gap among the approaches. Worth noting, the layer-based graphical model can distinguish direct and indirect studies on musical appreciations. Some investigations examine the relationship between the attributes of a layer and musical taste directly, while other studies concern the relationship between the attributes in different layers, indirectly cooperating in musical appreciation. This paper by introducing the three layers of determinants provides more comprehensive determinant categorizations. Furthermore, by having the graph in mind, the proposed model makes a platform to place the musical taste studies in the graph to reflect how the study is generally conducted, which attributes are considered appropriately during the study and which attributes needed to be concerned. The proposed layer-based model, provides a bedrock for further investigation, to design musical taste related studies more consciously.

In practice, the graph reflects some gaps among the studies, especially in the extra-music factors, to be later considered by scholars. For example, apart from not properly concerning the trace of environmental condition on the musical taste, it seems there is no significant classification for the environmental conditions at all. Enthusiastic scholars can develop some environmental categories and explore its effects on musical appreciations. In addition, there is no study summarizing the environmental attributes mentioned in the basic layer; there is a gap in the skimmed layer of external attributes. Consequently, the graph reflects some gaps among the studies on musical taste determinants.

All in all, the proposed model sheds further light on the determinants of our musical appreciations; it provides a more holistic perception of the conducted 
studies, and reflects the gap among them to be considered in future investigations. Consequently, this study by proposing a model illustrates how different approaches have explored musical appreciation; it shows how to develop future inquiries, to prevent the ignorance of influential factors and to fill the gap among the significant attributes. In brief, we hope this study by providing a more holistic understanding of the determinants brings about designing studies more consciously and prevent neglecting influential factors in future investigations.

\section{Conflicts of Interest}

The authors declare no conflicts of interest regarding the publication of this paper.

\section{References}

Aucouturier, J.-J., \& Pachet, F. (2003). Representing Musical Genre: A State of the Art. Journal of New Music Research, 32, 83-93. https://doi.org/10.1076/jnmr.32.1.83.16801

Backus, F. (2018). CBS News Asks: What Is America's Favorite Music Genre? CBS News Poll.

https://www.cbsnews.com/news/cbs-news-asks-what-is-americas-favorite-music-genre

Bailey, L. M. (1983). The Effects of Live Music versus Tape-Recorded Music on Hospitalized Cancer Patients. Music Therapy, 3, 17-28. https://doi.org/10.1093/mt/3.1.17

Bauer, A.-K. R., Kreutz, G., \& Herrmann, C. S. (2015). Individual Musical Tempo Preference Correlates with EEG Beta Rhythm. Psychophysiology, 52, 600-604. https://doi.org/10.1111/psyp.12375

Besson, M., \& Faïta, F. (1995). An Event-Related Potential (ERP) Study of Musical Expectancy: Comparison of Musicians with Nonmusicians. Journal of Experimental Psychology: Human Perception and Performance, 21, 1278-1296.

https://doi.org/10.1037/0096-1523.21.6.1278

Brecheisen, S., Kriegel, H.-P., Kunath, P., \& Pryakhin, A. (2006). Hierarchical Genre Classification for Large Music Collections. In IEEE International Conference on Multimedia and Expo (pp. 1385-1388). Toronto: IEEE. https://doi.org/10.1109/ICME.2006.262797

Broughton, M., \& Stevens, C. (2009). Music, Movement and Marimba: An Investigation of the Role of Movement and Gesture in Communicating Musical Expression to an Audience. Psychology of Music, 37, 137-153. https://doi.org/10.1177/0305735608094511

Cerulo, K. A. (1984). Social Disruption and Its Effects on Music: An Empirical Analysis. Social Forces, 62, 885-904. https://doi.org/10.2307/2578553

Cespedes-Guevara, J., \& Eerola, T. (2018). Music Communicates Affects, Not Basic Emotions-A Constructionist Account of Attribution of Emotional Meanings to Music. Frontiers in Psychology, 9, 215. https://doi.org/10.3389/fpsyg.2018.00215

Chamorro-Premuzic, T., Fagan, P., \& Furnham, A. (2010). Personality and Uses of Music as Predictors of Preferences for Music Consensually Classified as Happy, Sad, Complex, and Social. Psychology of Aesthetics, Creativity, and the Arts, 4, 205.

https://doi.org/10.1037/a0019210

Cheng, H.-T., Yang, Y.-H., Lin, Y.-C., Liao, I. B., \& Chen, H. H. (2008). Automatic Chord 
Recognition for Music Classification and Retrieval. In IEEE International Conference on Multimedia and Expo (pp. 1505-1508). Hannover: IEEE.

Condon, D. M. (2018). SAPA Project. https://sapa-project.org

Costa, Y. M. G., Oliveira, L. S., Koerich, A. L., \& Gouyon, F. (2012). Comparing Textural Features for Music Genre Classification. In The 2012 International Joint Conference on Neural Networks (pp. 1-6). Brisbane: IEEE. https://doi.org/10.1109/IJCNN.2012.6252626

Costa, Y. M. G., Oliveira, L. S., Koerich, A. L., Gouyon, F., \& Martins, J. G. (2012). Music Genre Classification Using LBP Textural Features. Signal Processing, 92, 2723-2737. https://doi.org/10.1016/j.sigpro.2012.04.023

Davies, J. B., \& Barclay, G. (1977). Consonance-Dissonance with Simultaneous Tones, and Fusion of Consecutive Tones. Psychology of Music, 5, 19-22. https://doi.org/10.1177/030573567751002

Davies, S. (2003). Themes in the Philosophy of Music. Oxford: Clarendon Press.

Delmonte, R. (2017). Music Consumption: The Overall Landscape. AudienceNet. https://musicbiz.org/wp-content/uploads/2017/09/MusicConsumptionTheOverallLand scape_AudienceNet.pdf

Droe, K. (2006). Music Preference and Music Education: A Review of Literature. Update: Applications of Research in Music Education, 24, 23-32. https://doi.org/10.1177/87551233060240020103

Eerola, T., \& Vuoskoski, J. K. (2013). A Review of Music and Emotion Studies: Approaches, Emotion Models, and Stimuli. Music Perception: An Interdisciplinary Journal, 30, 307-340. https://doi.org/10.1525/mp.2012.30.3.307

Evans, P., \& Schubert, E. (2008). Relationships between Expressed and Felt Emotions in Music. Musicae Scientiae, 12, 75-99. https://doi.org/10.1177/102986490801200105

Finnäs, L. (1989). How Can Musical Preferences Be Modified? A Research Review. Bulletin of the Council for Research in Music Education, No. 102, 1-58.

Foley, J. P. (1940). The Occupational Conditioning of Preferential Auditory Tempo: A Contribution toward an Empirical Theory of Aesthetics. The Journal of Social Psychology, 12, 121-129. https://doi.org/10.1080/00224545.1940.9713808

Friedman, R. S., Gordis, E., \& Förster, J. (2012). Re-Exploring the Influence of Sad Mood on Music Preference. Media Psychology, 15, 249-266. https://doi.org/10.1080/15213269.2012.693812

Frijda, N. H. (2008). The Psychologists' Point of View. In M. Lewis, J. M. Haviland-Jones, \& L. F. Barrett (Eds.), Handbook of Emotions (3rd ed., pp. 68-87). New York: Guilford Press.

Gabrielsson, A. (2001). Emotions in Strong Experiences with Music. https://doi.org/10.1037/t37570-000

Gabrielsson, A. (2002). Emotion Perceived and Emotion Felt: Same or Different? Musicae Scientiae, 5, 123-147. https://doi.org/10.1177/10298649020050S105

Gabrielsson, A., \& Lindström, E. (2001). The Influence of Musical Structure on Emotional Expression. In P. N. Juslin, \& J. A. Sloboda (Eds.), Music and Emotion: Theory and Research (pp. 223-248). Oxford: Oxford University Press.

Geringer, J. M. (1976). Tuning Preferences in Recorded Orchestral Music. Journal of Research in Music Education, 24, 169-176. https://doi.org/10.2307/3345127

Geringer, J. M. (2010). Musicians' Preferences for Tempo and Pitch Levels in Recorded 
Orchestral Music. Journal of Research in Music Education, 58, 294-308.

https://doi.org/10.1177/0022429410380464

Gordon, J., \& Gridley, M. C. (2013). Musical Preferences as a Function of Stimulus Complexity of Piano Jazz. Creativity Research Journal, 25, 143-146. https://doi.org/10.1080/10400419.2013.752303

Gosselin, P.-Y. L. (2017). The Effects of Language on English Language Learners' Music Preferences. International Journal of Music Education, 35, 216-226.

https://doi.org/10.1177/0255761415582346

Greasley, A. E., \& Lamont, A. M. (2006). Music Preference in Adulthood: Why Do We Like the Music We Do. In Proceedings of the 9th International Conference on Music Perception and Cognition, Alma Mater Studiorum, University of Bologna, Italym 960-966.

Greenberg, D. M., Baron-Cohen, S., Stillwell, D. J., Kosinski, M., \& Rentfrow, P. J. (2015). Musical Preferences Are Linked to Cognitive Styles. PLoS ONE, 10, e0131151. https://doi.org/10.1371/journal.pone.0131151

Greenberg, D. M., Kosinski, M., Stillwell, D. J., Monteiro, B. L., Levitin, D. J., \& Rentfrow, P. J. (2016). The Song Is You: Preferences for Musical Attribute Dimensions Reflect Personality. Social Psychological and Personality Science, 7, 597-605. https://doi.org/10.1177/1948550616641473

Hargreaves, D. J., MacDonald, R., \& Miell, D. (2005). How Do People Communicate Using Music. In D. Miell, R. MacDonald, \& D. J. Hargreaves (Eds.), Musical Communication (pp. 1-25). Oxford: Oxford University Press. https://doi.org/10.1093/acprof:oso/9780198529361.003.0001

Hevner, K. (1936). Experimental Studies of the Elements of Expression in Music. The American Journal of Psychology, 48, 246-268. https://doi.org/10.2307/1415746

Hevner, K. (1937). The Affective Value of Pitch and Tempo in Music. The American Journal of Psychology, 49, 621-630. https://doi.org/10.2307/1416385

Husain, G., Thompson, W. F., \& Schellenberg, E. G. (2002). Effects of Musical Tempo and Mode on Arousal, Mood, and Spatial Abilities. Music Perception: An Interdisciplinary Journal, 20, 151-171. https://doi.org/10.1525/mp.2002.20.2.151

John, O. P., \& Srivastava, S. (1999). The Big Five Trait Taxonomy: History, Measurement, and Theoretical Perspectives. In L. Pervin, \& O. P. John (Eds.), Handbook of Personality: Theory and Research (2nd ed., pp. 102-138). New York: Guilford Press.

Juslin, P. N., \& Laukka, P. (2004). Expression, Perception, and Induction of Musical Emotions: A Review and a Questionnaire Study of Everyday Listening. Journal of New Music Research, 33, 217-238. https://doi.org/10.1080/0929821042000317813

Juslin, P. N., \& Sloboda, J. A. (2001). Music and Emotion: Theory and Research. Oxford: Oxford University Press.

Konecni, V. J. (1982). Social Interaction and Musical Preference. In D. Deutsch (Ed.), The Psychology of Music (pp. 479-516). New York: Academic Press. https://doi.org/10.1016/B978-0-12-213562-0.50021-8

Langmeyer, A., Guglhör-Rudan, A., \& Tarnai, C. (2012). What Do Music Preferences Reveal about Personality? Journal of Individual Differences, 33, 119-130. https://doi.org/10.1027/1614-0001/a000082

LeBlanc, A. (1981). Effects of Style, Tempo, and Performing Medium on Children's Music Preference. Journal of Research in Music Education, 29, 143-156. https://doi.org/10.2307/3345023 
Leblanc, A. (1982). An Interactive Theory of Music Preference. Journal of Music Therapy, 19, 28-45. https://doi.org/10.1093/jmt/19.1.28

LeBlanc, A., \& McCrary, J. (1983). Effect of Tempo on Children's Music Preference. Journal of Research in Music Education, 31, 283-294. https://doi.org/10.2307/3344631

LeBlanc, A., \& Sherrill, C. (1986). Effect of Vocal Vibrato and Performer's Sex on Children's Music Preference. Journal of Research in Music Education, 34, 222-237. https://doi.org/10.2307/3345258

LeBlanc, A., Jin, Y. C., Stamou, L., \& McCrary, J. (1999). Effect of Age, Country, and Gender on Music Listening Preferences. Bulletin of the Council for Research in Music Education, No. 141, 72-76.

LeBlanc, A., Sims, W. L., Siivola, C., \& Obert, M. (1996). Music Style Preferences of Different Age Listeners. Journal of Research in Music Education, 44, 49-59.

https://doi.org/10.2307/3345413

Lin, C.-R., Liu, N.-H., Wu, Y.-H., \& Chen, A. L. P. (2004). Music Classification Using Significant Repeating Patterns. In International Conference on Database Systems for Advanced Applications (pp. 506-518). Berlin: Springer. https://doi.org/10.1007/978-3-540-24571-1_47

Lindström, E., Juslin, P. N., Bresin, R., \& Williamon, A. (2003). "Expressivity Comes from within Your Soul”: A Questionnaire Study of Music Students' Perspectives on Expressivity. Research Studies in Music Education, 20, 23-47. https://doi.org/10.1177/1321103X030200010201

Lippens, S., Martens, J.-P., \& De Mulder, T. (2004). A Comparison of Human and Automatic Musical Genre Classification. In IEEE International Conference on Acoustics, Speech, and Signal Processing (p. 4). Montreal: IEEE.

Lo, Y.-L., \& Lin, Y.-C. (2010). Content-Based Music Classification. In 3rd IEEE International Conference on Computer Science and Information Technology (Vol. 2, pp. 112-116). Chengdu: IEEE. https://doi.org/10.1109/ICCSIT.2010.5563642

Lopes, E. (2018). Most Popular Music Genres: It Is Completely Different than You Believe.

http://www.musicthinktank.com/blog/most-popular-music-genres-it-is-completely-dif ferent-than-yo.html

Marshall, S. R., \& Naumann, L. P. (2018). What's Your Favorite Music? Music Preferences Cue Racial Identity. Journal of Research in Personality, 76, 74-91. https://doi.org/10.1016/j.jrp.2018.07.008

Martindale, C., \& Moore, K. (1990). Intensity, Dissonance, and Preference for Pure Tones. Empirical Studies of the Arts, 8, 125-134. https://doi.org/10.2190/9X1D-0DDB-QRPH-AQQR

McCown, W., Keiser, R., Mulhearn, S., \& Williamson, D. (1997). The Role of Personality and Gender in Preference for Exaggerated Bass in Music. Personality and Individual Differences, 23, 543-547. https://doi.org/10.1016/S0191-8869(97)00085-8

McCrae, R. R. (2009). The Five-Factor Model of Personality Traits: Consensus and Controversy. In P. J. Corr, \& G. Matthews (Eds.), The Cambridge Handbook of Personality Psychology (pp. 148-161). Cambridge: Cambridge University Press. https://doi.org/10.1017/CBO9780511596544.012

McCrary, J. (1993). Effects of Listeners' and Performers' Race on Music Preferences. Journal of Research in Music Education, 41, 200-211. https://doi.org/10.2307/3345325

McKay, C., \& Fujinaga, I. (2006). Musical Genre Classification: Is It Worth Pursuing and 
How Can It Be Improved? In Proceeding of Seventh International Conference on Music Information Retrieval (pp. 101-106). ISMIR.

Miu, A. C., Pițur, S., \& Szentágotai-Tătar, A. (2016). Aesthetic Emotions across Arts: A Comparison between Painting and Music. Frontiers in Psychology, 6, 1951. https://doi.org/10.3389/fpsyg.2015.01951

Morrison, S. J. (1998). A Comparison of Preference Responses of White and African-American Students to Musical versus Musical/Visual Stimuli. Journal of Research in Music Education, 46, 208-222. https://doi.org/10.2307/3345624

Neuman, Y., Perlovsky, L., Cohen, Y., \& Livshits, D. (2016). The Personality of Music Genres. Psychology of Music, 44, 1044-1057. https://doi.org/10.1177/0305735615608526

Norman, W. T. (1963). Toward an Adequate Taxonomy of Personality Attributes: Replicated Factor Structure in Peer Nomination Personality Ratings. The Journal of $A b$ normal and Social Psychology, 66, 574-583. https://doi.org/10.1037/h0040291

North, A. C., \& Hargreaves, D. J. (1995). Subjective Complexity, Familiarity, and Liking for Popular Music. Psychomusicology: A Journal of Research in Music Cognition, 14, 77-93. https://doi.org/10.1037/h0094090

North, A. C., \& Hargreaves, D. J. (1996). Situational Influences on Reported Musical Preference. Psychomusicology: A Journal of Research in Music Cognition, 15, 30-45. https://doi.org/10.1037/h0094081

North, A., \& Hargreaves, D. (2008). The Social and Applied Psychology of Music. Oxford: Oxford University Press. https://doi.org/10.1093/acprof:oso/9780198567424.001.0001

Payne, E. (1980). Towards an Understanding of Music Appreciation. Psychology of Music, 8, 31-41. https://doi.org/10.1177/030573568082004

Pettijohn, T. F., Williams, G. M., \& Carter, T. C. (2010). Music for the Seasons: Seasonal Music Preferences in College Students. Current Psychology, 29, 328-345.

https://doi.org/10.1007/s12144-010-9092-8

Rawlings, D., \& Ciancarelli, V. (1997). Music Preference and the Five-Factor Model of the NEO Personality Inventory. Psychology of Music, 25, 120-132. https://doi.org/10.1177/0305735697252003

Rentfrow, P. J., \& Gosling, S. D. (2003). The Do Re Mi's of Everyday Life: The Structure and Personality Correlates of Music Preferences. Journal of Personality and Social Psychology, 84, 1236. https://doi.org/10.1037/0022-3514.84.6.1236

Rentfrow, P. J., Goldberg, L. R., \& Levitin, D. J. (2011). The Structure of Musical Preferences: A Five-Factor Model. Journal of Personality and Social Psychology, 100, 1139-1157. https://doi.org/10.1037/a0022406

Rentfrow, P. J., Goldberg, L. R., Stillwell, D. J., Kosinski, M., Gosling, S. D., \& Levitin, D. J. (2012). The Song Remains the Same: A Replication and Extension of the Music Model. Music Perception: An Interdisciplinary Journal, 30, 161-185. https://doi.org/10.1525/mp.2012.30.2.161

Rigg, M. G. (1940). Speed as a Determiner of Musical Mood. Journal of Experimental Psychology, 27, 566-571. https://doi.org/10.1037/h0058652

Rosner, A., Weninger, F., Schuller, B., Michalak, M., Kostek, B., Gruca, D. A., Kozielski, S. et al. (2014). Influence of Low-Level Features Extracted from Rhythmic and Harmonic Sections on Music Genre Classification (pp. 467-473). Cham: Springer International Publishing. https://doi.org/10.1007/978-3-319-02309-0_51

Rosner, B. S., \& Narmour, E. (1992). Harmonic Closure: Music Theory and Perception. 
Music Perception: An Interdisciplinary Journal, 9, 383-411. https://doi.org/10.2307/40285561

Schäfer, T., \& Sedlmeier, P. (2009). From the Functions of Music to Music Preference. Psychology of Music, 37, 279-300. https://doi.org/10.1177/0305735608097247

Schäfer, T., \& Sedlmeier, P. (2010). What Makes Us Like Music? Determinants of Music Preference. Psychology of Aesthetics, Creativity, and the Arts, 4, 223-234.

https://doi.org/10.1037/a0018374

Schäfer, T., Sedlmeier, P., Städtler, C., \& Huron, D. (2013). The Psychological Functions of Music Listening. Frontiers in Psychology, 4, Article 511. https://doi.org/10.3389/fpsyg.2013.00511

Schellenberg, E. G., \& Habashi, P. (2015). Remembering the Melody and Timbre, Forgetting the Key and Tempo. Memory \& Cognition, 43, 1021-1031. https://doi.org/10.3758/s13421-015-0519-1

Simonton, D. K. (1980). Thematic Fame and Melodic Originality in Classical Music: A Multivariate Computer-Content Analysis. Journal of Personality, 48, 206-219. https://doi.org/10.1111/j.1467-6494.1980.tb00828.x

Simonton, D. K. (1986). Aesthetic Success in Classical Music: A Computer Analysis of 1935 Compositions. Empirical Studies of the Arts, 4, 1-17. https://doi.org/10.2190/JLAP-JRK1-0TDY-DBRM

Sink, P. E. (1992). Research on Teaching Junior High and Middle School General Music. In R. Colwell (Ed.), Handbook of Research on Music Teaching and Learning: A Project of the Music Educators National Conference (p. 602). New York: Schirmer Books. https://books.google.com.tr/books?id=_lYYAQAAIAAJ

Swanson, A. (2015). Which Music Genres Have the Loyalest Fans? The Washington Post. https://www.washingtonpost.com/news/the-switch/wp/2015/04/03/charted-which-mus ic-genre-has-the-most-loyal-fans/

Tagg, P. (1982). Analysing Popular Music: Theory, Method and Practice. Popular Music, 2, 37-67. https://doi.org/10.1017/S0261143000001227

Teo, T. (2003). Relationship of Selected Musical Characteristics and Musical Preference: A Review of Literature. Visions of Research in Music Education, 3, 38-51.

Ter Bogt, T. F. M., Mulder, J., Raaijmakers, Q. A. W., \& Nic Gabhainn, S. (2011). Moved by Music: A Typology of Music Listeners. Psychology of Music, 39, 147-163.

https://doi.org/10.1177/0305735610370223

Tramo, M. J., Cariani, P. A., Delgutte, B., \& Braida, L. D. (2001). Neurobiological Foundations for the Theory of Harmony in Western Tonal Music. Annals of the New York Academy of Sciences, 930, 92-116. https://doi.org/10.1111/j.1749-6632.2001.tb05727.x

Tymoczko, D. (2010). A Geometry of Music: Harmony and Counterpoint in the Extended Common Practice. Oxford: Oxford University Press.

Vatolkin, I., Rötter, G., \& Weihs, C. (2014). Music Genre Prediction by Low-Level and High-Level Characteristics. In Data Analysis, Machine Learning and Knowledge Discovery (pp. 427-434). Berlin: Springer. https://doi.org/10.1007/978-3-319-01595-8_46

Vuoskoski, J. K., \& Eerola, T. (2011). The Role of Mood and Personality in the Perception of Emotions Represented by Music. Cortex, 47, 1099-1106.

https://doi.org/10.1016/j.cortex.2011.04.011

Vuoskoski, J. K., Thompson, W. F., McIlwain, D., \& Eerola, T. (2012). Who Enjoys Listening to Sad Music and Why? Music Perception: An Interdisciplinary Journal, 29, 311-317. https://doi.org/10.1525/mp.2012.29.3.311 
Wapnick, J. (1976). A Review of Research on Attitude and Preference. Bulletin of the Council for Research in Music Education, No. 48, 1-20.

http://www.jstor.org/stable/40317417

Wapnick, J. (1980). Pitch, Tempo, and Timbral Preferences in Recorded Piano Music. Journal of Research in Music Education, 28, 43-58. https://doi.org/10.2307/3345052

Yarbrough, C. (1987). The Effect of Musical Excerpts on Tempo Discriminations and Preferences of Musicians and Non-Musicians. In C. K. Madsen, \& C. A. Prickett (Eds.), Applications of Research in Music Behavior (pp. 175-189). Tuscaloosa, AL: University of Alabama.

Yu, L., \& Kang, J. (2010). Factors Influencing the Sound Preference in Urban Open Spaces. Applied Acoustics, 71, 622-633. https://doi.org/10.1016/j.apacoust.2010.02.005

Zentner, M. R., \& Kagan, J. (1998). Infants' Perception of Consonance and Dissonance in Music. Infant Behavior and Development, 21, 483-492.

https://doi.org/10.1016/S0163-6383(98)90021-2 